\title{
Association of PTEN expression with liver function and inflammatory changes in patients with liver cancer after chemotherapy
}

\author{
JIXIANG ZHOU and XIAOLI LI \\ Department of Hepatobiliary Surgery, Xiangya Hospital, Central South University, \\ Changsha, Hunan 410008, P.R. China
}

Received March 28, 2018; Accepted September 7, 2018

DOI: $10.3892 / 01.2018 .9458$

\begin{abstract}
This study investigated the effects of phosphatase and tensin homolog deleted on chromosome ten (PTEN) expression on liver function classification, serum tumor markers and liver function of patients with liver cancer. A total of 63 patients with primary liver cancer treated in Xiangya Hospital (Changsha, China) were retrospectively analyzed. The difference in the PTEN expression levels in normal liver cells and liver cancer cells was compared via immunohistochemistry. According to the expression level of PTEN in the patient's pathological report, patients were divided into PTEN-positive and PTEN-negative groups. The expression level of each tumor marker in serum of patients was observed, and the association of PTEN expression level with the serum tumor markers was analyzed. Moreover, the changes in liver function and inflammatory factors before and after chemotherapy were compared. Finally, the relationship between the PTEN expression level and Child-Pugh grading of the liver function was detected. Compared with that in normal liver cells, the positive expression rate of PTEN protein in liver cancer cells was significantly decreased $(\mathrm{P}<0.05)$. No significant difference was found in the expression levels of serum tumor markers, except $\alpha$-fetoprotein (AFP) in liver cancer patients between PTEN-positive and PTEN-negative group, indicating that PTEN expression has no significant effects on serum tumor markers. The levels of albumin (ALB), alkaline phosphatase (ALP) and prothrombin activity (PTA) were decreased significantly after chemotherapy compared with those before chemotherapy $(\mathrm{P}<0.05)$. Besides, the levels of inflammatory factors were remarkably reduced
\end{abstract}

Correspondence to: Dr Xiaoli Li, Department of Hepatobiliary Surgery, Xiangya Hospital, Central South University, 87 Xingya Road, Changsha, Hunan 410008, P.R. China

E-mail: xiangyalx11216@126.com

Key words: liver cancer, PTEN, Child-Pugh grading, serum tumor markers, inflammatory factors after chemotherapy. PTEN expression was negatively associated with liver function grading, and the higher the PTEN expression, the lower the liver function grading was. The low expression of PTEN has a certain association with the occurrence and grading of liver cancer. PTEN gene has guiding significance in predicting the occurrence, development and prognosis of liver cancer.

\section{Introduction}

Liver cancer, including hepatocellular carcinoma (HCC) and intrahepatic cholangiocarcinoma, is one of the common malignant tumors of the digestive tract in China, with mortality rate as high as $42.5 \%$, second only to esophageal and gastric cancer. The most important risk factors for liver cancer are hepatitis B virus and alcoholism. According to the results of an epidemiological survey, the increased content of organic chlorides and DDT in drinking water and aflatoxin in food are also major factors inducing liver cancer (1). It has also been reported that the occurrence of liver cancer may be related to the difference in gene expression levels in patients, in which the abnormal activation of Wnt/ $\beta$-catenin signaling pathway and expression deletion of the phosphatase and tensin homolog deleted on chromosome ten (PTEN) and other tumor suppressor genes can mediate the occurrence of liver cancer $(2,3)$. PTEN, discovered in 1997, is a tumor suppressor gene with dual-specificity phosphatase activity located on chromosome 10, which can dephosphorylate downstream phosphatidylinositol 3,4,5-trisphosphate in normal liver tissues, thus blocking the downstream phosphatidylinositol 3-kinase/protein kinase B (PI3K/Akt) signaling pathway, and negatively regulating the growth of liver cells. In case of deletion or mutation of PTEN, however, its negative regulatory effect on downstream pathway will disappear or decline, and the normal regulatory mechanism for cell growth or metastasis will be lost, thereby inducing the occurrence or malignant transformation of tumors $(4,5)$. At present, it has been confirmed that the abnormal expression of PTEN is associated with the occurrence and development of a variety of malignant tumors, such as glioma, endometrial, liver and prostate cancers $(6,7)$. In this study, the expression of PTEN in normal liver cells and liver cancer cells was retrospectively 
analyzed to investigate the possible associations of PTEN with the incidence of liver cancer, liver function grading and liver function.

\section{Patients and methods}

General patient data. A total of 63 patients diagnosed with primary liver cancer via preoperative puncture or postoperative pathological diagnosis in Xiangya Hospital were enrolled, including 37 males and 26 females aged 30-82 years with an average of $48.5 \pm 8.6$ years. The hospitalization duration was 2.4-6.3 years with an average of 4.6 \pm 2.7 years. All patients underwent surgical resection after preoperative chemotherapy. No abdominal visceral metastasis and lymph node metastasis were found, and there were no other tumors, except liver cancer, during operation. The study was approved by the Ethics Committee of Xiangya Hospital, Central South University (Changsha, China). Signed informed consents were obtained from the patients or the guardians

Research methods. All patients enrolled in this study were treated with preoperative chemotherapy using cisplatin (CDDP) once per month (3-4 times as one course of treatment). After 2-3 courses of chemotherapy, the patients that satisfied the surgical indications received surgical resection. After operation, the specimens were fixed in $40 \%$ formalin at $25^{\circ} \mathrm{C}$ for $24 \mathrm{~h}$, collected, dehydrated, and prepared into $3-\mu \mathrm{M}$ sections, followed by routine hematoxylin and eosin (H\&E) staining and immunohistochemical staining. The positive control was set. The tissue was blocked with $10 \% \mathrm{FBS}$ at $20^{\circ} \mathrm{C}$ for $10 \mathrm{~min}$, then incubated with rabbit anti-human PTEN monoclonal antibody (cat. no. 9559, 1:50; Cell Signaling Technology, Inc., Danvers, MA, USA) at $4^{\circ} \mathrm{C}$ for $12 \mathrm{~h}$, and washed with PBS for $10 \mathrm{~min}, 3$ times. The tissue was then incubated with secondary antibody SignalStain ${ }^{\circledR}$ Boost IHC Detection Reagent (HRP, rabbit) (cat. no. 8114, 1:500; Cell Signaling Technology, Inc.) at $20^{\circ} \mathrm{C}$ for $1 \mathrm{~h}$. Serum tumor markers, blood biochemical factors and inflammatory factors in patients were detected via chemiluminescence. Fasting venous blood was drawn from patients at 1 week before and after chemotherapy, and the supernatant was taken after centrifugation at $6,000 \mathrm{x}$ g at $4^{\circ} \mathrm{C}$ for $15 \mathrm{~min}$ for on-machine detection. Before chemotherapy, the liver function of patients was scored according to the Child-Pugh grading: grade A, 5-6 points; grade B, 7-9 points; and grade $\mathrm{C}$, 10-15 points.

Observation indexes. Interpretation of results: PTEN displayed brown-yellow particles in immunohistochemistry, and the expression of PTEN in liver cancer cells was observed under high-power field by a light microscope (x100): $\mathrm{PTEN}^{++}$, percentage of positive cells $>50 \%$; $\mathrm{PTEN}^{+}$, percentage of positive cells $>10-50 \%$; and $\mathrm{PTEN}^{-}$, percentage of positive cells $<10 \%$. In this study, the percentage of positive cells $>10 \%$ indicted positive PTEN expression.

Statistical methods. GraphPad 5.0 software (GraphPad Software, Inc., La Jolla, CA, USA) was used for the statistical analysis of data. t-test was used for measurement data and Chi-square test for enumeration data. One-way analysis of variance was used for multiple comparisons and Tukey's test
Table I. Comparison of PTEN protein expression in normal liver tissues and liver cancer tissues.

\begin{tabular}{lcc}
\hline & \multicolumn{2}{c}{ PTEN [n (\%)] } \\
\cline { 2 - 3 } Type of tissue & - & + \\
\hline Normal liver tissues $(\mathrm{n}=63)$ & $3(4.76)$ & $60(95.23)$ \\
Liver cancer tissues $(\mathrm{n}=63)$ & $34(53.97)$ & $29(46.03)$ \\
$\chi^{2}$ & & 34.43 \\
P-value & & 0.0001 \\
\hline
\end{tabular}

PTEN, phosphatase and tensin homolog deleted on chromosome ten.

Table II. Comparison of serum tumor marker levels with PTEN expression before operation (mean \pm SD).

\begin{tabular}{lcc}
\hline Serum tumor marker & PTEN $(-)$ & PTEN $(+)$ \\
\hline AFP $(\mathrm{ng} / \mathrm{ml})$ & $167.4 \pm 45.6$ & $110.5 \pm 32.1^{\mathrm{a}}$ \\
CA125 $(\mathrm{U} / \mathrm{ml})$ & $143.5 \pm 25.7$ & $139.7 \pm 13.6$ \\
CEA $(\mathrm{ng} / \mathrm{ml})$ & $31.4 \pm 6.7$ & $34.5 \pm 3.2$ \\
CA199 $(\mathrm{U} / \mathrm{ml})$ & $51.3 \pm 9.7$ & $48.6 \pm 4.8$ \\
CA153 $(\mathrm{U} / \mathrm{ml})$ & $45.6 \pm 8.9$ & $50.6 \pm 5.7$ \\
\hline
\end{tabular}

${ }^{\text {a }}<0.05$ vs. PTEN-negative group. PTEN, phosphatase and tensin homolog deleted on chromosome ten; AFP, $\alpha$-fetoprotein.

was the post hoc test used. $\mathrm{P}<0.05$ suggested that the difference was statistically significant.

\section{Results}

Expression of PTEN in normal liver tissues and liver cancer tissues. In the 63 specimens of this study, the positive expression rate of PTEN was $95.23 \%$ in normal liver tissues, but only $46.03 \%$ in liver cancer tissues, suggesting that the positive expression rate of PTEN in liver cancer tissues was significantly decreased, and the difference was statistically significant $(\mathrm{P}<0.05)$ (Table I).

Comparison of serum tumor marker levels between the two groups of patients. After chemotherapy, liver cancer patients were divided into PTEN-positive and PTEN-negative groups according to the expression of PTEN. There was no statistically significant difference in the levels of serum tumor markers between the two groups of patients after chemotherapy ( $\mathrm{P}>0.05)$, but the level of $\alpha$-fetoprotein (AFP) in PTEN-positive group was obviously lower than that in PTEN-negative group $(\mathrm{P}<0.05)$ (Table II).

Comparison of changes in liver function of patients before and after chemotherapy. After chemotherapy, the expression levels of serum alanine transaminase (ALT) and aspartate transaminase (AST) in patients were slightly increased, which might be related to side-effects of chemotherapy drugs on the liver. The results were not statistically different from those before chemotherapy. After chemotherapy, the levels of 
Table III. Comparison of changes in the liver function of patients before and after chemotherapy (mean $\pm \mathrm{SD}$ ).

\begin{tabular}{lcc}
\hline $\begin{array}{l}\text { Serum biochemical } \\
\text { index of liver }\end{array}$ & $\begin{array}{c}\text { Before } \\
\text { chemotherapy }\end{array}$ & $\begin{array}{c}\text { After } \\
\text { chemotherapy }\end{array}$ \\
\hline ALT (U/l) & $387.5 \pm 103.4$ & $413.6 \pm 110.7$ \\
AST (U/l) & $396.4 \pm 98.4$ & $428.7 \pm 104.3$ \\
ALB (U/1) & $38.5 \pm 7.3$ & $23.5 \pm 6.2^{\mathrm{a}}$ \\
ALP (g/l) & $237.8 \pm 84.8$ & $165.4 \pm 57.1^{\mathrm{a}}$ \\
PTA (\%) & $134.9 \pm 23.4$ & $83.5 \pm 18.6^{\mathrm{a}}$ \\
\hline
\end{tabular}

${ }^{\mathrm{a}} \mathrm{P}<0.05$ vs. before chemotherapy. ALT, alanine transaminase; AST, aspartate transaminase; ALB, albumin; ALP, alkaline phosphatase; PTA, prothrombin activity.

Table IV. Association between PTEN expression and liver function classification.

\begin{tabular}{lcc}
\hline Child-Pugh grading & $\begin{array}{c}\text { Positive PTEN } \\
\text { expression [n (\%)] }\end{array}$ & $\mathrm{n}$ \\
\hline A & $11(78.57)$ & 14 \\
B & $13(46.43)^{\mathrm{a}}$ & 28 \\
C & $5(23.8)^{\mathrm{a}}$ & 21
\end{tabular}

${ }^{\text {aP }}<0.05$ vs. grade A. PTEN, phosphatase and tensin homolog deleted on chromosome ten.

Table V. Comparison of serum inflammatory factors in patients with liver cancer before and after chemotherapy (mean $\pm \mathrm{SD}$ ).

\begin{tabular}{lcc}
\hline $\begin{array}{l}\text { Inflammatory } \\
\text { factor }\end{array}$ & $\begin{array}{c}\text { Before } \\
\text { chemotherapy }\end{array}$ & $\begin{array}{c}\text { After } \\
\text { chemotherapy }\end{array}$ \\
\hline IL-1 $(\mathrm{ng} / \mathrm{l})$ & $5.46 \pm 0.23$ & $3.27 \pm 0.19^{\mathrm{b}}$ \\
IL-6 $(\mathrm{ng} / \mathrm{l})$ & $183.47 \pm 29.36$ & $26.83 \pm 9.26^{\mathrm{b}}$ \\
$\mathrm{IL}-2(\mu \mathrm{g} / \mathrm{ml})$ & $217.45 \pm 76.21$ & $165.43 \pm 91.3^{\mathrm{a}}$ \\
$\mathrm{IL}-12(\mathrm{pg} / \mathrm{ml})$ & $256.56 \pm 98.34$ & $182.17 \pm 86.47^{\mathrm{a}}$ \\
$\mathrm{IL}-10(\mathrm{ng} / \mathrm{ml})$ & $274.65 \pm 79.28$ & $173.54 \pm 69.7^{\mathrm{b}}$ \\
MIF $(\mathrm{ng} / \mathrm{ml})$ & $25.42 \pm 6.95$ & $10.32 \pm 4.31^{\mathrm{b}}$ \\
\hline
\end{tabular}

${ }^{\mathrm{a}} \mathrm{P}<0.05,{ }^{\mathrm{b}} \mathrm{P}<0.001$ vs. before chemotherapy. IL, interleukin.

albumin (ALB), alkaline phosphatase (ALP) and prothrombin activity (PTA) in patients were obviously decreased, and there were statistically significant differences compared with those before chemotherapy $(\mathrm{P}<0.05)$ (Table III).

Association between PTEN expression and liver function classification. There were varying degrees of changes in the liver function of patients with liver cancer, among which the PTEN positive rate was $78.57 \%$ in patients in grade A, $46.43 \%$ in patients in grade B and $23.8 \%$ in patients in grade $\mathrm{C}$. With the increase of Child-Pugh grading of patients with liver cancer, the positive expression rate of PTEN in patients

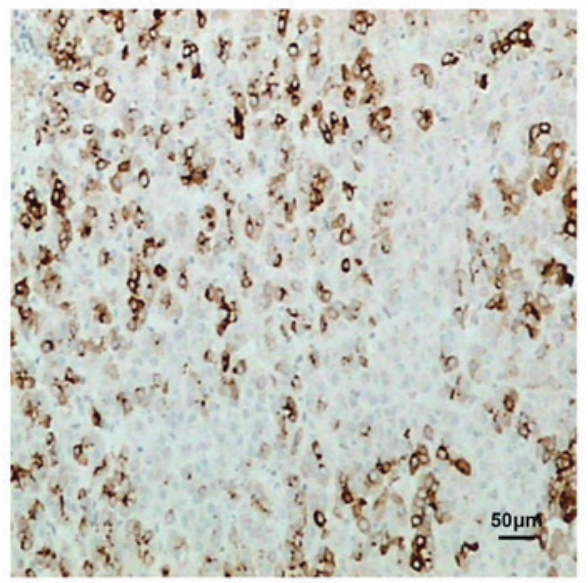

Figure 1. PTEN expression in normal liver tissues (x100). PTEN, phosphatase and tensin homolog deleted on chromosome ten.

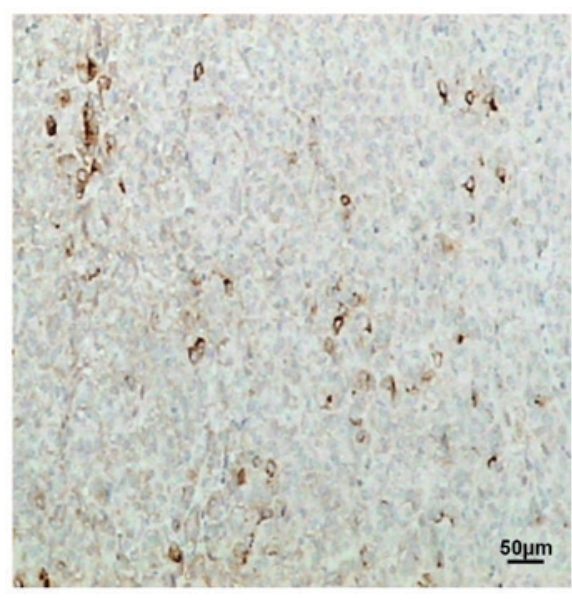

Figure 2. PTEN expression in liver cancer tissues (x100). PTEN, phosphatase and tensin homolog deleted on chromosome ten.

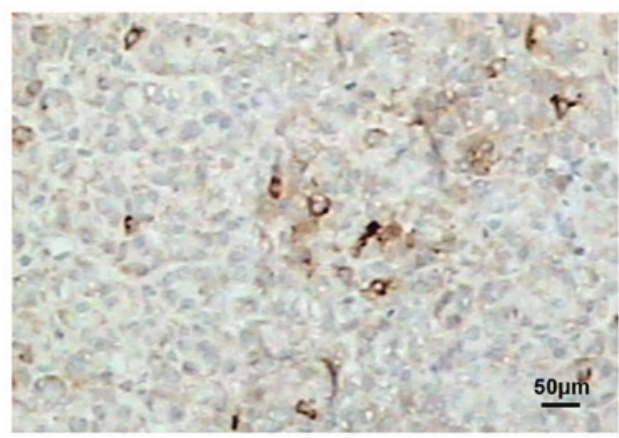

Figure 3. PTEN expression in liver cancer tissues after chemotherapy (x100). PTEN, phosphatase and tensin homolog deleted on chromosome ten.

was decreased, displaying a negative association between them (Table IV).

Comparison of serum inflammatory factors in patients with liver cancer before and after chemotherapy. Detection results of serum biochemical indexes in patients at 1 week before and after chemotherapy manifested that the levels of inflammatory factors in peripheral blood of patients after chemotherapy 
were remarkably lower than those before chemotherapy, and differences were statistically significant $(\mathrm{P}<0.05$ or $\mathrm{P}<0.001)$ (Table V).

Association between PTEN expression and liver cancer tissues. Immunohistochemical results revealed that PTEN was mainly localized in the cytoplasm, and also slightly in the nucleus. Compared with those in normal liver tissues, the expression of PTEN in liver cancer tissues before and after chemotherapy was obviously reduced (Figs. 1-3).

\section{Discussion}

PTEN is a tumor suppressor gene with dual-specificity phosphatase activity, which is involved in the growth, proliferation, adhesion, migration, differentiation and apoptosis of normal cells and plays important roles in these processes $(8,9)$. Therefore, the role of PTEN gene deletion and mutation in tumorigenesis has attracted the attention of many researchers. At present, a certain progress has been made in the research on the phosphorylase activity and substrate of PTEN in tumor cells and the role of PTEN in signal transduction pathway in various tumor cells (10). Through the in vitro nerve cell experiment, Weng et al have confirmed that PTEN leads to the decline in the activation and phosphorylation of glycogen synthase kinase 3 (GSK3) through the PI3K/AKT signaling pathway. Due to the decreased phosphorylation of GSK3 for downstream cyclin D1, more cyclin D1 is accumulated in cells, thus arresting cells in G1 phase (11). According to results of research on glioblastoma, PTEN can inhibit cell growth and migration via regulating focal adhesion kinase (FAK) and p130 cas tyrosine phosphorylation $(12,13)$. In breast cancer cells, PTEN, through affecting the insulin receptor IRS-1 phosphorylation and the formation of IRS-1/Grb2/SOS complex, blocking Gab1 migration, and other pathways, can inhibit mitogen-activated protein kinase (MAPK) activity, and reduce the positive regulatory effects of MAPK signaling pathway on cell growth, proliferation and differentiation (14). It has also been reported that PTEN plays a role in prostate cancer, in which PTEN can increase the sensitivity of prostate cancer cells to apoptosis receptor- and drug-mediated Fas-associated protein with death domain (FADD)-dependent apoptosis signaling pathway, making a breakthrough in the treatment of prostate cancer (15). Therefore, PTEN gene has a close association with the occurrence and development of tumors. It has been reported that the positive expression rate of PTEN protein in HCC tissues is markedly lower than that in para-carcinoma normal tissues, and even not expressed in cancer tissues (16). The expression of PTEN is negatively associated to HCC pathological grading and the presence of cancer thrombus. The positive expression rates of PTEN in patients in Child-Pugh grade $\mathrm{C}$ and $\mathrm{B}$ are significantly lower than that in patients in grade $\mathrm{A}$, and $\mathrm{HCC}$ patients with low or negative PTEN protein expression are often accompanied by the elevated level of AFP and the metastasis of cancer cells. However, there are no definite reports on the relationships of the positive expression rate of PTEN with HCC size, serum AFP level and pathological typing (17). The results of this study manifested that the expression of PTEN in liver cancer tissues was mainly located in the cytoplasm, and slightly in the nucleus, which are consistent with the results previously reported in the literature (18-20). Compared with that in normal liver tissues, the expression of PTEN in HCC was remarkably decreased, and the difference was statistically significant $(\mathrm{P}<0.05)$. No significant differences were found in the expression levels of serum tumor markers, except AFP, in HCC patients with negative PTEN expression compared with those in HCC patients with positive PTEN expression, indicating that PTEN expression basically has no effect on the levels of serum tumor markers in $\mathrm{HCC}$, but the expression of AFP is significantly increased in HCC patients with negative PTEN expression. Whether PTEN is related to the expression level of AFP and the way in which it affects the expression of AFP remain to be further investigated. Moreover, there was no significant change in blood biochemical indexes in patients after chemotherapy. The levels of ALT and AST in HCC patients were slightly increased after chemotherapy, which was possibly due to the side-effects of chemotherapy drugs on the liver. The expression levels of ALB, ALP and PTA and inflammatory factors (IL-1 and IL-2) were obviously decreased after chemotherapy, and there were statistically significant differences compared with those before chemotherapy $(\mathrm{P}<0.05)$. The expression of PTEN was negatively associated with the Child-Pugh grading of liver function, which was obviously lower in HCC patients in grade B and $\mathrm{C}$ than that in patients in grade $\mathrm{A}$, indicating that the expression of PTEN has a certain effect on the liver function of HCC patients. In conclusion, the association of the expression of PTEN with the liver function classification, serum tumor markers and liver function of HCC patients is described above, providing experimental data for predicting the clinical progression and prognosis of HCC. PTEN can serve as a potential gene in the biologically targeted therapy of liver cancer.

\section{Acknowledgements}

Not applicable.

\section{Funding}

This study was supported by the Hunan Natural Sciences Foundation Key Program (no. 2017JJ3504).

\section{Availability of data and materials}

The datasets used and/or analyzed during the present study are available from the corresponding author on reasonable request.

\section{Authors' contributions}

JZ and XL drafted the manuscript. They also recorded and analyzed the expression of PTEN and the liver function. Both authors read and approved the final manuscript.

\section{Ethics approval and consent to participate}

The study was approved by the Ethics Committee of Xiangya Hospital, Central South University (Changsha, China). Signed informed consents were obtained from the patients or the guardians. 


\section{Patient consent for publication}

Not applicable.

\section{Competing interests}

The authors declare that they have no competing interests.

\section{References}

1. Gravitz L: Liver cancer. Nature 516: S1, 2014.

2. Shibata T, Chuma M, Kokubu A, Sakamoto M and Hirohashi S: EBP50, a beta-catenin-associating protein, enhances Wnt signaling and is over-expressed in hepatocellular carcinoma. Hepatology 38: 178-186, 2003.

3. Alioui A, Dufour J, Leoni V, Loregger A, Moeton M, Iuliano L, Zerbinati C, Septier A, Val P, Fouache A, et al: Liver X receptors constrain tumor development and metastasis dissemination in PTEN-deficient prostate cancer. Nat Commun 8: 445, 2017.

4. Seo JH, Ahn Y, Lee SR, Yeol Yeo C and Chung Hur K: The major target of the endogenously generated reactive oxygen species in response to insulin stimulation is phosphatase and tensin homolog and not phosphoinositide-3 kinase (PI-3 kinase) in the PI-3 kinase/Akt pathway. Mol Biol Cell 16: 348-357, 2005.

5. Furnari FB, Lin H, Huang HS and Cavenee WK: Growth suppression of glioma cells by PTEN requires a functional phosphatase catalytic domain. Proc Natl Acad Sci USA 94 12479-12484, 1997.

6. Dahia PL: PTEN, a unique tumor suppressor gene. Endocr Relat Cancer 7: 115-129, 2000.

7. Steck PA, Pershouse MA, Jasser SA, Yung WKA, Lin H, Ligon AH, Langford LA, Baumgard ML, Hattier T, Davis T, et al: Identification of a candidate tumour suppressor gene, MMAC1, at chromosome 10q23.3 that is mutated in multiple advanced cancers. Nat Genet 15: 356-362, 1997.

8. Shearn CT and Petersen DR: Understanding the tumor suppressor PTEN in chronic alcoholism and hepatocellular carcinoma. Adv Exp Med Biol 815: 173-184, 2015.

9. Lu DD, Zhang XR and Cao XR: Expression and significance of new tumor suppressor gene PTEN in primary liver cancer. J Cell Mol Med 7: 67-71, 2003.

10. Li J, Yen C, Liaw D, Podsypanina K, Bose S, Wang SI, Puc J, Miliaresis C, Rodgers L, McCombie R, et al: PTEN, a putative protein tyrosine phosphatase gene mutated in human brain, breast, and prostate cancer. Science 275: 1943-1947, 1997.
11. Weng L, Brown J and Eng C: PTEN induces apoptosis and cell cycle arrest through phosphoinositol-3-kinase/Akt-dependent and -independent pathways. Hum Mol Genet 10: 237-242, 2001.

12. Tamura M, Gu J, Takino T and Yamada KM: Tumor suppressor PTEN inhibition of cell invasion, migration, and growth: Differential involvement of focal adhesion kinase and p130Cas. Cancer Res 59: 442-449, 1999.

13. Zhang L, Yu Q, He J and Zha X: Study of the PTEN gene expression and FAK phosphorylation in human hepatocarcinoma tissues and cell lines. Mol Cell Biochem 262: 25-33, 2004.

14. Weng LP, Smith WM, Brown JL and Eng C: PTEN inhibits insulin-stimulated MEK/MAPK activation and cell growth by blocking IRS-1 phosphorylation and IRS-1/Grb-2/Sos complex formation in a breast cancer model. Hum Mol Genet 10: 605-616, 2001.

15. Yuan XJ and Whang YE: PTEN sensitizes prostate cancer cells to death receptor-mediated and drug-induced apoptosis through a FADD-dependent pathway. Oncogene 21: 319-327, 2002.

16. Rahman MA, Kyriazanos ID, Ono T, Yamanoi A, Kohno H, Tsuchiya $M$ and Nagasue N: Impact of PTEN expression on the outcome of hepatitis C virus-positive cirrhotic hepatocellular carcinoma patients: Possible relationship with COX II and inducible nitric oxide synthase. Int J Cancer 100: 152-157, 2002.

17. Wan XW, Jiang M, Cao HF, He YQ, Liu SQ, Qiu XH, Wu MC and Wang HY: The alteration of PTEN tumor suppressor expression and its association with the histopathological features of human primary hepatocellular carcinoma. J Cancer Res Clin Oncol 129: 100-106, 2003.

18. Ginn-Pease ME and Eng C: Increased nuclear phosphatase and tensin homologue deleted on chromosome 10 is associated with $\mathrm{G}_{0}-\mathrm{G}_{1}$ in MCF-7 cells. Cancer Res 63: 282-286, 2003.

19. Yeh KT, Chang JG, Chen YJ, Chen ST, Yu SY, Shih MC, Perng LI, Wang JC, Tsai M and Chang CP: Mutation analysis of the putative tumor suppressor gene PTEN/MMAC1 in hepatocellular carcinoma. Cancer Invest 18: 123-129, 2000.

20. Yao YJ, Ping XL, Zhang H, Chen FF, Lee PK, Ahsan H, Chen CJ, Lee PH, Peacocke M, Santella RM, et al: PTEN/MMAC1 mutations in hepatocellular carcinomas. Oncogene 18: 3181-3185, 1999.

This work is licensed under a Creative Commons Attribution-NonCommercial-NoDerivatives 4.0 International (CC BY-NC-ND 4.0) License. 